Volume 2, Number 2, 2016

\title{
Analysis of Fuzzy Controller Application Efficiency in Two-Mass Systems with Variable Moment of Inertia of Second Mass
}

\author{
Andrew Lozynskyy, Lyubomyr Demkiv ${ }^{*}$ \\ Lviv Polytechnic National University, Stepan Bandera St., 12, Lviv, 79013, Ukraine
}

Received: November 3, 2016. Revised: December 22, 2016. Accepted: December 26, 2016.

(C) 2016 The Authors. Published by Lviv Polytechnic National University.

\begin{abstract}
A two-mass system with variable moment of inertia of the second mass has been considered. Common approaches to controller synthesis of such system were considered. A fuzzy robust controller was introduced. Comparison of the proposed approach with the classic one has been conducted. Corresponding conclusions about the feasibility of the proposed approach were done. The cases of a system with dynamic reference and without it were considered. Besides, a linear and nonlinear behavior of the second mass of the system was taken into account. Obtained results testify that implementation of the proposed controlled can provide a significant gain in the transients of the investigated system.
\end{abstract}

Keywords: FLC; robust controller; two-mass system; MPC controller.

\section{Introduction}

While developing new and improving the existing electromechanical systems the researchers pay particular attention to the matter of stabilization and response speed of the systems, controllers of which are generated for certain sets of the parameters values of these systems. However, within performance of numerous systems (for example, excavating machine, tube railroad, continuum robot manipulator, etc.) the values of the systems parameters change due to the operational peculiarities. In such a case, it appears to be necessary to generate the robust control, i.e. control providing stability of the system while the values of its parameters change.

There exist a lot of approaches to generation of such control. Particularly, in paper [2] the $H_{2} / H_{\infty}$ methods for generation of the robust controller have been applied. In paper [1], there has been researched generation of the $H_{\infty}$ robust fuzzy controller for the fuzzy system by means of observer that allowed narrowing the task to searching for the optimal limited control. In paper [3], there has been generated fuzzy robust controller by applying LQR theory and LMI approach. In paper [4], for the synthesis of the robust controller, it has been offered to find out the optimal control of the auxiliary problem that ensures the robustness of the source system. Application of the sliding mode system of robust control generation has been also applied in papers [5,6]. In paper [7], in order to control the continuum robot manipulator the robust controller consisting of the relay controller and fuzzy compensator has been applied. Unfortunately, due to the complexity of the studied object the rule base of the proposed fuzzy controller consists of 49 rules and that essentially complicates application of the mentioned approach in respect of the other objects. The similar approach has been also applied in paper [8] where the robust controller used to operate the robot has been generated by means of the compensator. In paper [9], there has been generated the robust controller consisting of usual PD and fuzzy controllers for the tracking control system ensuring convergence of the tracking error.

In case of induction motors, in order to generate the controller, the FOC (field oriented control) (see [10]) and ADRC (auto-disturbance rejection controller) (see [11]) have been applied; that demonstrated that the mentioned approaches ensure the robust of the generated controllers.

Another approach is to use MPC controller. This approach was used in particular in the papers [12-14]. Radius of system stability is an important issue in the study of systems with variable parameters. The paper [15] has investigated nonautonomous systems and suggested theoretical approaches to evaluation of the stability radius of such systems.

"Corresponding author. Email address: demkivl@gmail.com 
The approach to the application of fuzzy logics for the synthesis of robust systems controllers has become broadly used. In particular, in the paper [16] an approach to synthesis of such controller has been suggested and the theorems indicating to its robustness have been proven. However, the conditions imposed on the matrixes in this article, including commutativity, cause doubts in the possibility of widespread use of the results obtained there. Moreover, the article has been dealing with the fuzzy system while it has been suggested to apply digital, relay controller. The ideas taken as the basis of this paper partially coincide with the ideas of [17] where fuzzy controller has been synthesized for bilinear systems with delay, only one variable which has two terms has been fuzzified. However, the suggested controller consists of matrixes, which choice has not been discussed in the said article. In addition, it is possible to use neural networks for robust controller synthesis, which have been suggested in [18] for the case of nonlinear systems with stochastic uncertainties.

The goal of this paper is to analyze the behavior of the system with variable moment of inertia of the second math with fuzzy controller.

\section{Statement of a problem}

A two -mass model is used in the study of the overwhelming majority of electromechanical systems. In these cases, the first mass is responsible for the joint inertia of the motor and the second mass for the load inertia. A detailed description of two-mass systems is given, for example, in [19]. Schematic representation of such system is shown, for instance, in [12] (see Figure 1).

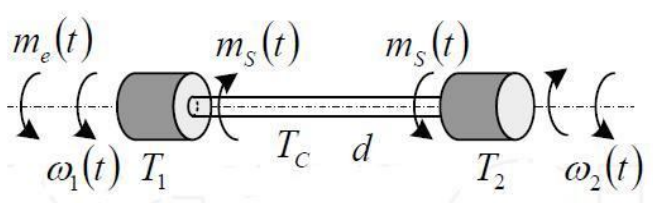

Fig.1. Typical scheme of a two-mass system

A linear mathematical model of such system is described as follows

$$
\frac{d}{d t}\left(\begin{array}{l}
\omega_{1}(t) \\
M_{12}(t) \\
\omega_{2}(t)
\end{array}\right)=\left(\begin{array}{ccc}
0 & -\frac{1}{T_{M_{1}}} & 0 \\
\frac{1}{T_{C}} & 0 & -\frac{1}{T_{C}} \\
0 & \frac{1}{T_{M_{2}}} & 0
\end{array}\right)\left(\begin{array}{l}
\omega_{1}(t) \\
M_{12}(t) \\
\omega_{2}(t)
\end{array}\right)+\left(\begin{array}{l}
\frac{1}{T_{M_{1}}} \\
0 \\
0
\end{array}\right) M_{1}(t)+\left(\begin{array}{l}
0 \\
-\frac{1}{T_{M 2}} \\
0
\end{array}\right) M_{C}(t)
$$

where the given variables are standardized quantities, a physical value of which depends on the type of two-mass system: with elastic deformations of twisting, stretching or bending, etc. In particular, in the case of two-mass system with elastic deformations of twisting $T_{M 1}, T_{M 2}$ - time constants of the first and the second masses, respectively, and $T_{C}$ - the time constant of the spring element, $\omega_{1}(p)$ and $\omega_{2}(p)$ - angular velocities at the ends of the flexible shaft, $M_{12}$ the moment of the spring element, $M_{1}$ - standardized time of engine, $M_{C}$ - standardized time of external disturbances. We will disregard friction forces in the suggested model.

The research will be held for the case when in the process of use the second mass time constant value can undergo changes. This may occur, for example, in the process of soil scooping by the excavator, during freight shifting by the robotic arm, or, for instance, when helical conveyer transfers grain.

To compare the system performance with synthesized controllers, the value of the integral performance index and penalty function has been calculated.

$$
I^{*}=I+F_{\text {penalty }}=\left(\gamma_{1} \int_{0}^{T} t|e(t)| d t\right)+\left(\gamma_{2}\left(\frac{x_{1}(t)}{x_{1, \max }}\right)^{2} H\left(\frac{x_{1}(t)}{x_{1, \max }}\right)+\gamma_{3}\left(\frac{x_{3}(t)}{x_{3, \max }}\right)^{2} H\left(\frac{x_{3}(t)}{x_{3, \max }}\right)\right),
$$

where $I$ - classical integral performance index (see [12], [23], for instance), where $H(\cdot)$ - is a Heaviside function, $x_{1, \max }, x_{3, \max }-$ specified maximum permissible overshoots and in the present case they make up $10 \%$ and $5 \%$ respectively, 
$x_{1, \max }^{t} x_{1, \text { min }}^{t}$ maximum and minimum value of $x_{1}(t)$ after first achieving of the set value by the initial coordinate. Coefficients $\gamma_{i}, i=\overline{1 . .5}$ have been chosen for reasons of proportionality of the studied variables with each other.

\section{Presentation of the main material}

There are many approaches to the robust control synthesis. This article presents a comparative study of some of these approaches such as predictive control (see [12], for instance), optimal robust control [20] and fuzzy robust control as suggested by the authors.

\subsection{Predictive control (MPC controller)}

As stated in $[12,13]$ in particular, this approach uses mainly linear discrete state-space system model

$$
\begin{aligned}
& x(k+1)=A x(k)+B u(k) \\
& y(k)=C x(k)
\end{aligned}
$$

where $x(k), u(k), y(k)$ - are vectors of state, system inputs and outputs respectively. Let us assume that $y_{k}-$ is an output signal value in future time $k$ at a given sequence $u_{k}$ and system's initial state $x_{0}$. Then, at every instant $k$ according to the predictive control algorithm the following optimization problem should be solved

$$
\begin{array}{ll}
\min _{u_{0}, \ldots, u_{N_{c}-1}} \sum_{k=0}^{N_{p}} y_{k}^{T} Q y_{k}+\sum_{k=0}^{N_{c}-1} u_{k}^{T} R u_{k} \\
u_{\min } \leq u_{k} \leq u_{\max }, \quad k=0, \ldots N_{c}-1 \\
y_{\min } \leq y_{k} \leq y_{\max }, \quad k=0, \ldots N_{p} \\
x_{k+1}=A x_{k}+B u_{k}, \quad k \geq 0 \\
y_{k}=C x_{k}, & k \geq 0 \\
x_{0}=x(0) &
\end{array}
$$

where $Q \geq 0, R>0$ - are weight matrixes, $N_{p}$ and $N_{c}$ - predictive and control horizons respectively, $u_{\min }, u_{\max }, y_{\min }, y_{\text {max }}$ - restrictions to the values of system input and output signals.

Let us introduce auxiliary output variables

$$
y_{1}(t)=\omega_{1}(t)-\omega_{r e f}(t), y_{2}(t)=M_{12}(t)-M_{C}(t), y_{3}(t)=\omega_{2}(t)-\omega_{r e f},
$$

here $y_{1}, y_{3}$ are responsible for the accuracy of transient process, while $y_{2}$ - for imbalance of shaft load torque. Decrease of the objective function value in MPC algorithm automatically provides for reduction of difference between the specified and actual values of both velocities and reduces torsional stresses.

According to [12], the choice of predictive and control horizons value is a compromise between the quality of transients in the system and the complexity of calculations, so it is advisable to choose $N_{c} \leq N_{p}$. Dynamic characteristics of the studied system with MPC controller can be customized by changing the values of the matrix elements $Q$. These values have been found in the work [12] using the pattern search algorithms.

\subsection{Optimal robust controller}

Another approach to synthesis of robust controller is suggested in [20]. It allows ensuring robust control in cases where variable parameters are in both the system matrix and the input matrix. The system studied in this paper can be written as follows

$$
\dot{x}=A(p) x+B u \text {. }
$$

It is obvious that in case of the studied system (1.1) representation of $A(p)-A\left(p_{0}\right)=B \varphi(p)$ is impossible, where $p_{0}$ is a nominal quantity value, and $\varphi(p)$ - limited matrix of the corresponding size. It is easy to make sure that $\left(A\left(p_{0}\right), B\right)$ is stabilizable, and matrix $A\left(p_{0}\right)$ is limited. In fact, the problem is to find such a vector of control $u=K x$ that would provide asymptotic stability of the closed system for all $p \in P$.

$$
\dot{x}=A(p) x+B K x
$$


In the event of the robust control synthesis it has been suggested in [20] to introduce the following notations for pseudoinverse matrix $B^{+}=\left(B^{T} B\right)^{-1} B^{T}$, and to define matrixes $F$ and $H$ in the following way

$$
\begin{aligned}
& \left(A(p)-A\left(p_{0}\right)\right)^{T} B^{+T} B^{+}\left(A(p)-A\left(p_{0}\right)\right) \leq F \\
& \alpha^{-2}\left(A(p)-A\left(p_{0}\right)\right)^{T}\left(A(p)-A\left(p_{0}\right)\right) \leq H
\end{aligned}
$$

where $\alpha \geq 0-$ a specific parameter.

Let us consider auxiliary system

$$
\dot{x}=A(p) x+B u+\alpha\left(I-B B^{+}\right) v
$$

for which you should find a controls relative to a full state vector $u=K x, v=L x$, which would minimize the objective function value

$$
\int_{0}^{\infty}\left(x^{T}\left(F+\rho^{2} H+\beta^{2} I\right) x+u^{T} u+\rho^{2} v^{T} v\right) d t \quad,
$$

where $\alpha \geq 0, \rho \geq 0, \beta \geq 0$ - some constant parameters.

The solution of the LQR task is

$$
\left[\begin{array}{l}
u \\
v
\end{array}\right]=-\tilde{R}^{-1} \tilde{B}^{T} S x
$$

where $S$ is the only positively defined solution of such algebraic Riccati equation

$$
S \tilde{A}+\tilde{A}^{T} S+\tilde{Q}+S \tilde{B} \tilde{R}^{-1} \tilde{B}^{T} S=0 .
$$

In case of the studied system

$$
\begin{aligned}
& \tilde{A}=A\left(p_{0}\right), \quad \tilde{B}=\left[\begin{array}{ll}
B & \alpha\left(I-B B^{+}\right)
\end{array}\right] \\
& \tilde{Q}=F+\rho^{2} H+\beta^{2} I, \quad \tilde{R}=\left[\begin{array}{cc}
I & 0 \\
0 & \rho^{2} I
\end{array}\right]
\end{aligned}
$$

Having considered that it has been shown in [4] that

$$
\left[\begin{array}{l}
u \\
v
\end{array}\right]=\left[\begin{array}{l}
-B^{T} S \\
-\alpha \rho^{2}\left(I-B B^{+}\right) S
\end{array}\right] x=\left[\begin{array}{l}
K \\
L
\end{array}\right] x
$$

In this work it has been proven that the parameter values $\alpha, \rho$ and $\beta$ should be chosen in such a way that the solution of task (1.4) - (1.5) $u=K x, v=L x$ satisfied the inequality

$$
\beta^{2} I-2 \rho^{2} L^{T} L>0,
$$

vector of control actions $u=K x$ will be simultaneously the solution to the robust control task (1.3).

\subsection{Fuzzy robust controller}

The same way as in previous cases, general view of the studied system is (1.3) and control relative to full state vector is applied. Since it is not always possible to measure real values of all intermediate coordinates in real systems, one may use the Kalman filter for this purpose.

The research has been conducted for the case when the variable parameter was the time constant of the second mass. Let us assume that $T_{M_{2}} \in\left[T_{M_{2}}^{0} ; T_{M_{2}}^{N}\right]$. In general, it is believed that the robust controller is a kind of the controller that ensures adequate quality of control, such as stability margin if the controlled object differs from the expected one. The control synthesized for some value of $T_{M_{2}}^{j}$ variable has a certain stability margin, i.e. if the real value of $T_{M_{2}}$ variable deviates from $T_{M_{2}}^{j}$ for some $\rho\left(T_{M_{2}}^{j}\right)$ value, the system remains stable. This value is called the 
radius of stability (see, for example [21]). In the event of $\Delta T_{M_{2}}^{i}=T_{M_{2}}^{i+1}-T_{M_{2}}^{i}>\rho\left(T_{M_{2}}^{i}\right)$, the system loses its stability. To determine the stability radius of the system, the Tsypkin-Polyak hodograph can be used, for example (see [21]). The value of $T_{M_{2}}$ parameter can be established by using, for example, the extended Kalman filter or Luneburg determinant. In addition, the value of $T_{M_{2}}$ can be determined based on the position of the electromechanical system, including auger, continuum robot manipulator, etc. (see e.g. [22]).

The idea of the suggested approach consists in the synthesis of the control actions with such $T_{M_{2}}^{i}$ values so that $T_{M_{2}}^{i+1}<T_{M_{2}}^{i}+\rho\left(T_{M_{2}}^{0}\right)$, which will ensure the robustness of the system. Thus, a transition from the studied system to the family of sub-systems with the same control object and various control actions will be actually done. For smooth switching between the subsystems a fuzzy sets theory apparatus will be used.

During synthesis of fuzzy controller for the studied system we should firstly specify its main degrees of freedom. Defuzzification will be conducted in a simplified gravitational method. General view of the $i^{\text {th }}$ rule has the view

$$
R_{i}: \text { IF } x_{r} \text { in TM } M_{i} \text { THEN } \bar{u}=K_{i} \bar{x}
$$

where $x_{r}$ - is the output signal of the second mass integrator, $T M_{i}$ - term of the corresponding fuzzy change, $K_{i}-$ matrix synthesized for $T_{M_{2}}=T_{M_{2}}^{i}$ value.

The membership function depicted in Figure 2 has been used for fuzzification.

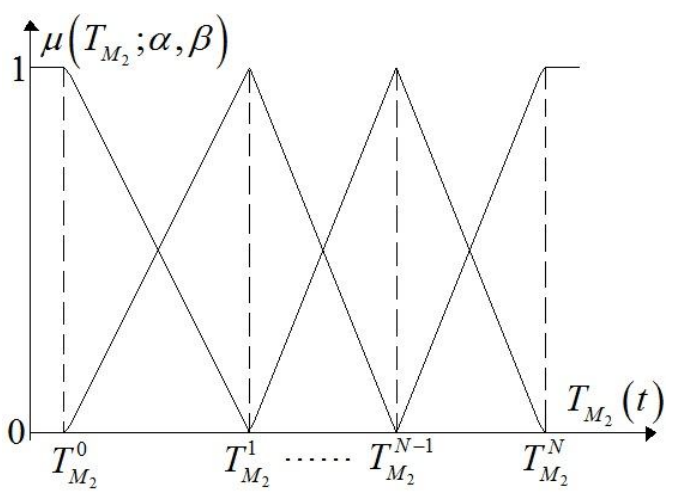

Fig.2 Membership function.

Thus, the studied system will become as follows

$$
\dot{x}=A(p) x+B \frac{\sum_{i=0}^{N} K_{i} \mu_{i}\left(T_{M_{2}}\right)}{\sum_{i=0}^{N} \mu_{i}\left(T_{M_{2}}\right)} x .
$$

\section{Research results}

The research has been conducted on the example of the system described in [12]. It should be noted that in the said article the studied model of the system with relevant parameters was tried in a real test facility. During the study. it has been set $T_{M_{1}}=203 \mathrm{~ms}, T_{C}=2.6 \mathrm{~ms}, T_{M_{2}} \in[203 \mathrm{~ms}, 812 \mathrm{~ms}]$. The value of mean geometric root has been defined to be equal to $\omega_{0}=15$.

In case of MPC controller according to [12] $\operatorname{diag}(Q)=[9188,184.0429,206948]$. Synthesis of MPC controller has been carried out with the help of MPC Toolbox in MatLab.

At synthesis of optimal robust controller there is a need in choosing values of constant parameters. If we base our choice of parameters as specified in [20], we will define $\alpha=0.05, \beta=10, \rho=1$. $F=0, H=\alpha^{-2}\left[H_{i j}\right]_{i, j=1 . .3}, H_{i j}=((\operatorname{pmax}-1) / \operatorname{Tm} 2)^{2}$. 
At synthesis of fuzzy robust control, as described above, the Tsypkin-Polyak hodograph has been applied to determine the stability radius. As the coefficients of range $\alpha=\left[0.001 ; 0.78 \cdot 10^{-1} ; 0.030^{*} 10^{-1} ; 0.000015\right]$ values have been selected. It is worth stating that under the conditions of the theorem $\alpha_{0}>0$, so we define $\alpha_{0}=0.001$.

What is more, the value of the stability interval can be determined by calculating the real parts of the roots of the characteristic polynomial of the system under investigation in case of its parameter values change. Specifically, Figure 4a shows the change of the stability radius values (Ro) in the event of $T_{M_{2}}$ and $\omega_{0}$ values change. In Figure 4, the time constant value, for which the controller gain has been synthesized, was indicated through $T_{M_{2}}$, and the real value of the second mass time constant was indicated through $T_{M_{2}}^{*}$.

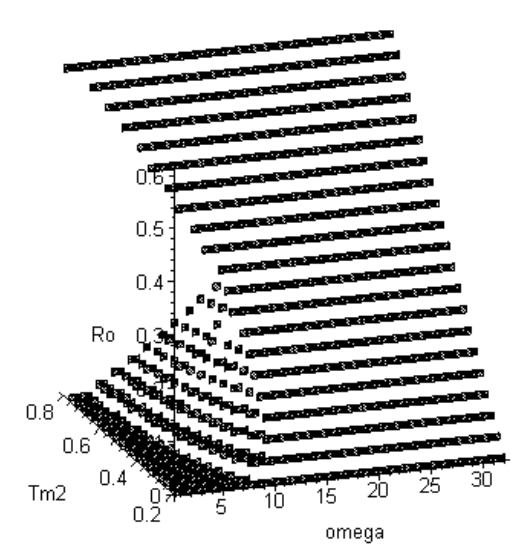

a

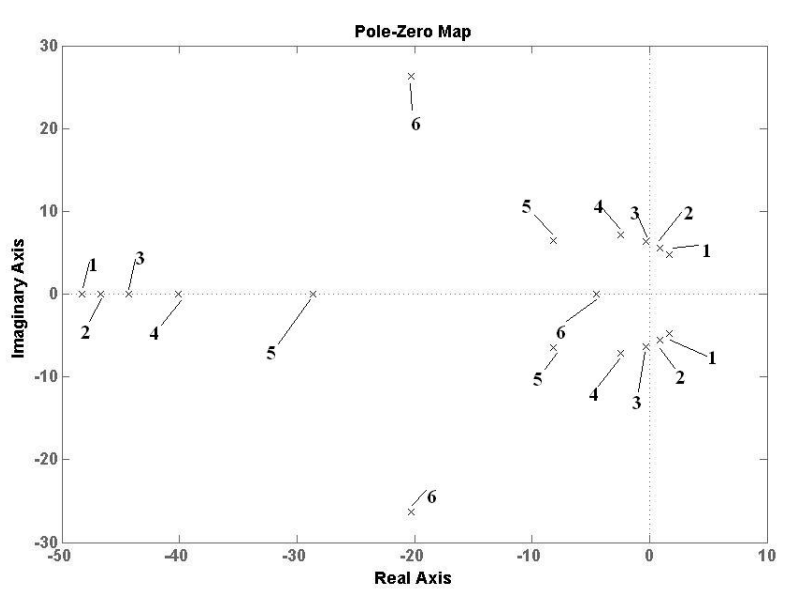

b

Fig.4. a -change of Ro stability radius value in the event of $T_{M_{2}}$ and $\omega_{0}$ values change; $\mathrm{b}$ - change of the characteristic polynomial roots position of the studied system in the event of the second mass time constant value change $1-T_{M_{2}}^{*}=0.203,6$ -

$$
T_{M_{2}}^{*}=0.812 \text {, other values } T_{M_{2}}^{*} \text { are uniformly distributed in the interval }(0.203,0.812)
$$

The provided results show that the $\omega_{0}$ value has a significant impact on the stability radius of the system. In particular, in the event when $\omega_{0}>20$, the system remains stable for all values of $T_{M_{2}}^{*}$ and $T_{M_{2}}$ from the studied interval of their change. For a more detailed impact the chart of the roots change has been provided where $\omega_{0}=15$ (see Figure 4b), in particular with the growth of the $T_{M_{2}}^{*}$ value, the system passes from an unstable state to a stable one, which is fully consistent with Figure 4a.

Figure 5 simultaneously shows variation in time of the input system signal and the second mass time constant value change $T_{M_{2}}(t)$. Since the scale of change of each value is different (and it is convenient to place them on the same chart), the chart has been depicted in relative units for descriptive reasons. It is worth noting that the value of the integral performance index (1.2) has been separately calculated for the segment of the input signal change: $I_{i}$ where $t \in\left[t_{i}, t_{i+1}\right], \hat{I}=\sum_{i=1}^{n} I_{i}$.

The two options of the input signal have been studied: with dynamic reference value and without it. The dynamics of the reference value is described by the second order term:

$$
G=\frac{\hat{\omega}_{0}^{2}}{p^{2}+2 \zeta \hat{\omega}_{0} p+\hat{\omega}_{0}^{2}},
$$

where $\hat{\omega}_{0}=32$, the reference frequency damping factor $\zeta=5$. 


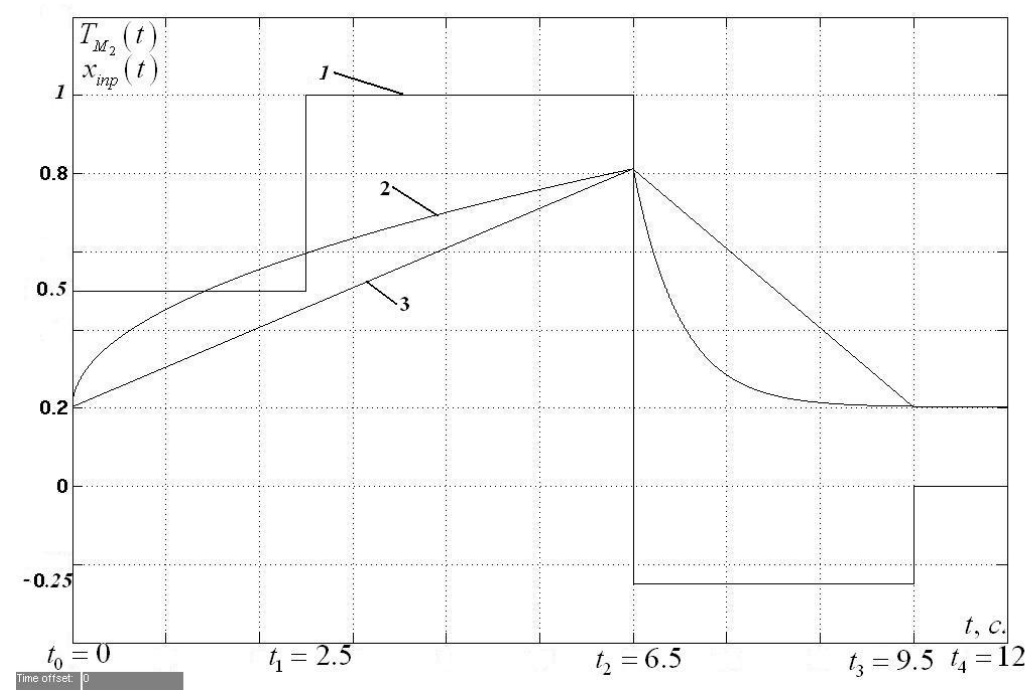

Fig.5. 1 - Input signal of the system; 2 and 3 - non-linear and linear functions $T_{M_{2}}(t)$ correspondingly.

The research has been conducted for the case where the function $T_{M_{2}}$ throughout whole simulation time takes a constant value. The survey results are shown in Figure 6.

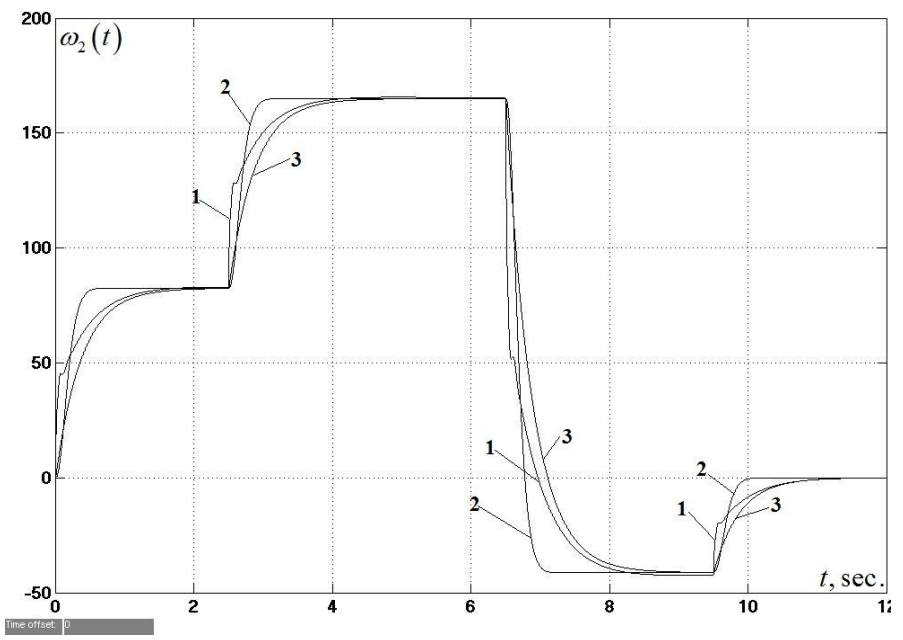

Fig.6. Transient processes in the system without dynamic reference in case when $T_{M_{2}}(t)=$ const ; $1-$ MPC controller, $2-$ fuzzy controller, 3 - optimal controller

In addition, the research has been conducted for the case when the function of variation in time parameter $T_{M_{2}}$ change is piecewise linear, which is shown in Figure 7a, and Figure 7b shows transient processes in the system in case when $T_{M_{2}}(t)$ is nonlinear.

For quantitative comparison of the results, $I_{i}$ value has been presented in Table 1 from (1.2). 


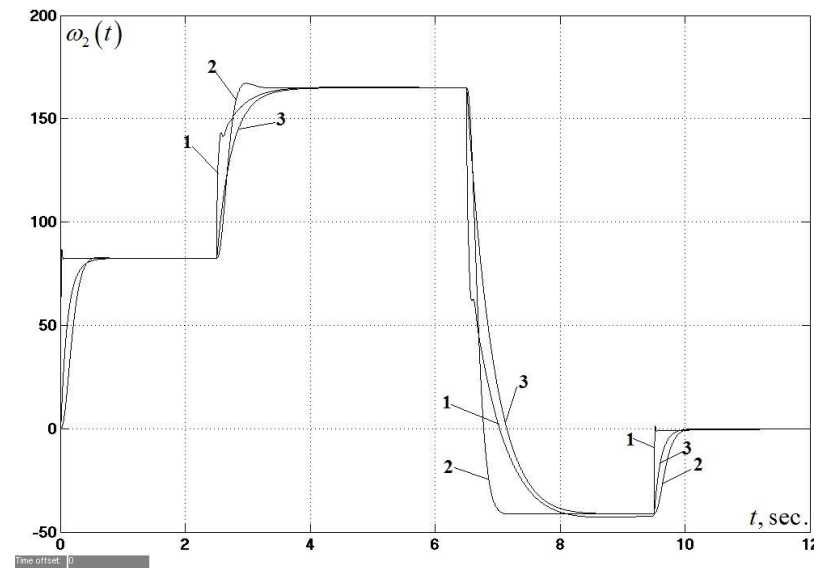

a)

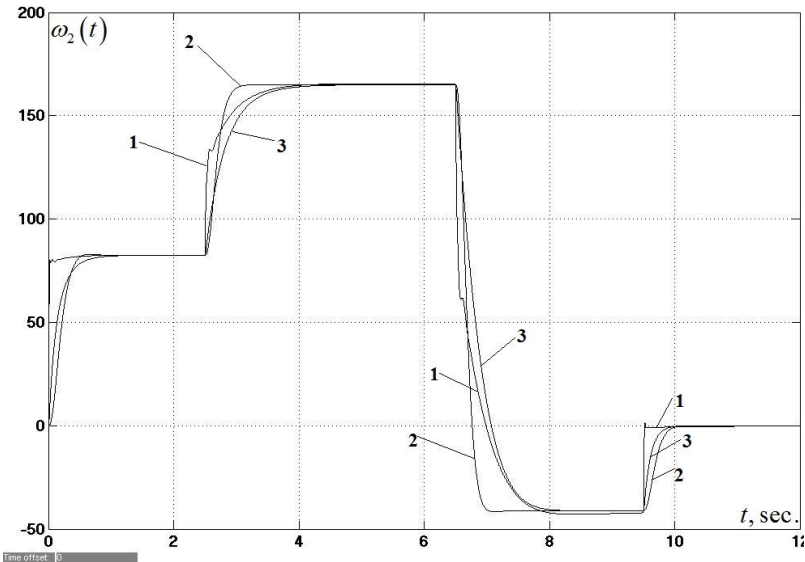

b)

Fig.7. Transient processes in the system without dynamic reference in case when function $T_{M_{2}}(t)$ is

a) piecewise linear b) nonlinear; 1 - MPC controller, 2 - fuzzy controller, 3 - optimal controller

Table 1. Quantitative indicators of system operation without dynamic reference

\begin{tabular}{|c|c|c|c|c|c|c|c|c|c|c|c|c|c|c|c|}
\hline \multirow{3}{*}{ Type of controller } & \multicolumn{15}{|c|}{ Behavior of the second mass time constant value } \\
\hline & \multicolumn{5}{|c|}{ Nonlinear } & \multicolumn{5}{|c|}{ Linear } & \multicolumn{5}{|c|}{ Constant } \\
\hline & $I_{1}$ & $I_{2}$ & $I_{3}$ & $I_{4}$ & $\hat{I}$ & $I_{1}$ & $I_{2}$ & $I_{3}$ & $I_{4}$ & $\hat{I}$ & $I_{1}$ & $I_{2}$ & $I_{3}$ & $I_{4}$ & $\hat{I}$ \\
\hline MPC & 4.68 & 12.29 & 22.28 & 1.87 & 41.12 & 4.38 & 9.21 & 26.23 & 2.05 & 41.87 & 12.3 & 14.85 & 23.21 & 5.61 & 55.97 \\
\hline Fuzzy & 2.33 & 2.22 & 4.66 & 1.1 & 10.31 & 2.07 & 1.87 & 5.09 & 1.1 & 10.13 & 2.07 & 2.07 & 5.17 & 1.03 & 10.34 \\
\hline Optimal & 2.36 & 9.19 & 21.8 & 0.51 & 33.86 & 1.19 & 5.45 & 29.47 & 0.51 & 36.62 & 11.74 & 11.87 & 29.56 & 5.86 & 59.03 \\
\hline
\end{tabular}

The results provided in the table show that the system with fuzzy controller provides a gain in operation speed compared to other systems with other studied controllers. It follows from the provided graphic material that in the case of MPC controller application, unacceptable variations of $\omega_{1}(t)$ occur. It should be noted that these variations can be eliminated by introducing limitations on intermediate coordinates into MPC controller; however it will reduce system performance. In case of necessity, it is also possible to introduce limitations on intermediate coordinates in the system with fuzzy controller, using, for instance, a cascade fuzzy controller.

Similar research has been conducted for the system with dynamical reference value. The corresponding results are provided in Figures 8-9 and in Table 2.

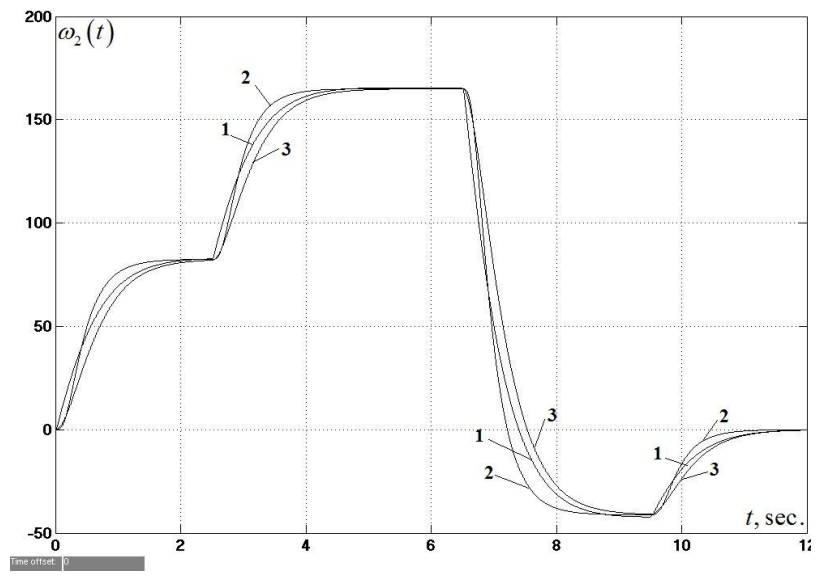

Fig.8. Transient processes in the system with dynamic reference in case when $T_{M_{2}}(t)=$ const $; 1-$ MPC controller, $2-$ fuzzy controller, 3 - optimal controller 


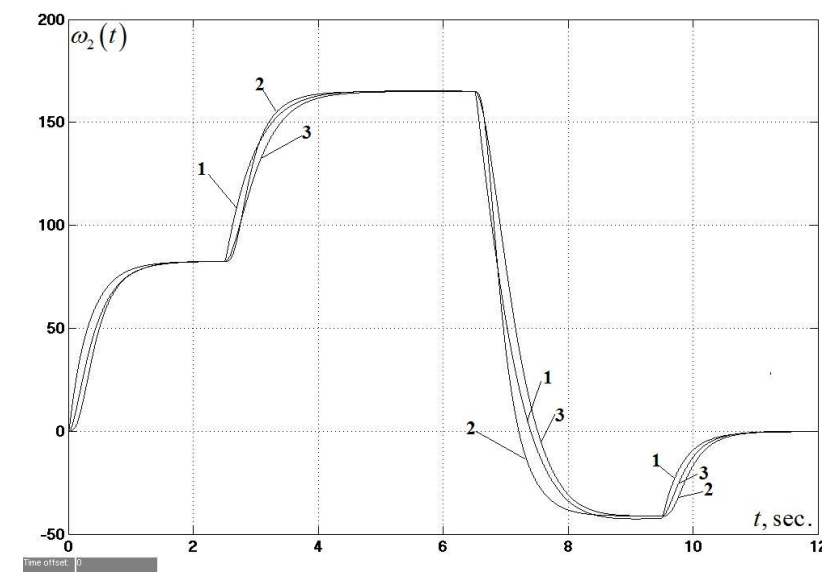

a)

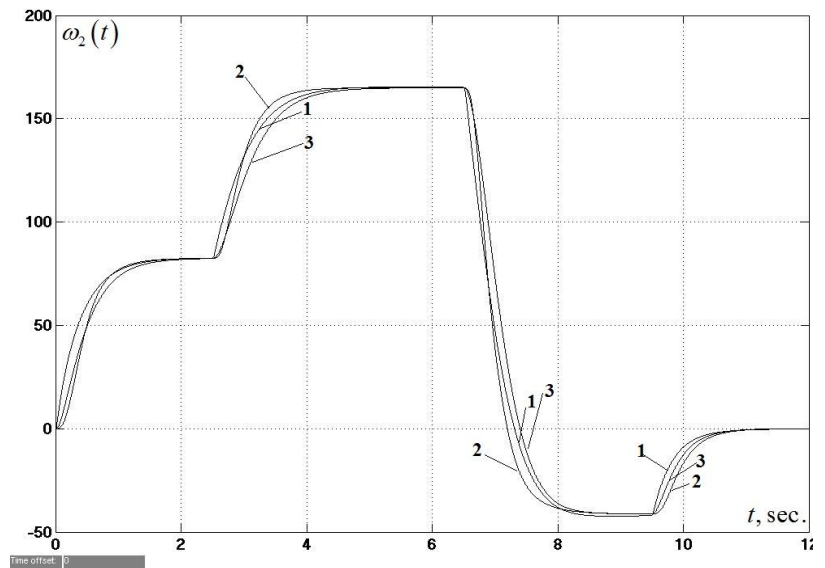

b)

Fig.9. Transient processes in the system with dynamic reference in case when function $T_{M_{2}}(t)$ is a) piecewise linear b) nonlinear; 1 - MPC controller, 2 - fuzzy controller, 3 - optimal controller

For quantitative comparison of the results, $I_{i}$ value has been presented in Table 2 from (1.2).

Table 2. Quantitative indicators of system operation with dynamical reference

\begin{tabular}{|c|c|c|c|c|c|c|c|c|c|c|c|c|c|c|c|}
\hline \multirow{3}{*}{$\begin{array}{l}\text { Controller } \\
\text { type }\end{array}$} & \multicolumn{15}{|c|}{ Behavior of the second mass time constant value } \\
\hline & \multicolumn{5}{|c|}{ Constant } & \multicolumn{5}{|l|}{ Linear } & \multicolumn{5}{|c|}{ NonlinearConstant } \\
\hline & $I_{1}$ & $I_{2}$ & $I_{3}$ & $I_{4}$ & $\hat{I}$ & $I_{1}$ & $I_{2}$ & $I_{3}$ & $I_{4}$ & $\hat{I}$ & $I_{1}$ & $I_{2}$ & $I_{3}$ & $I_{4}$ & $\hat{I}$ \\
\hline MPC & 21.41 & 22.93 & 54.95 & 12.17 & 111.46 & 9.132 & 15.97 & 53.55 & 5.289 & 83.941 & 11.72 & 20.36 & 43.6 & 4.941 & 80.62 \\
\hline Fuzzy & 15.04 & 15.09 & 37.69 & 7.519 & 75.339 & 14.73 & 14.17 & 37.05 & 7.641 & 73.591 & 14.26 & 15.28 & 35.34 & 7.641 & 72.52 \\
\hline Optimal & 29.15 & 29.77 & 73.81 & 14.52 & 147.25 & 13.44 & 21.59 & 66.97 & 5.957 & 107.96 & 17.25 & 26.96 & 53.49 & 5.957 & 103.66 \\
\hline
\end{tabular}

These results allow making similar conclusions as in the case of the system without dynamical reference.

It is worth mentioning that in contrast to the digital controllers the performance in the suggested fuzzy controller can be improved by applying a different type of characteristic polynomial, according to which subsystems are configured, or by applying a combination of such polynomials. There has also been a research conducted of the system behavior with periodic change in the behavior of the relevant system parameter. The behavior of the initial coordinate of the studied system in this case for the suggested fuzzy controller was not different from the above.

\section{Conclusions}

The results demonstrate the applicability of the suggested approach to the robust controller synthesis since the use of the fuzzy sets theory apparatus allows us to significantly increase system performance against the background of missing impermissible variations of both initial and intermediate coordinates.

It was shown that proposed approach increase an efficiency of the system up to $30 \%$ in comparison with optimal robust controller and up to $11 \%$ in case of MPC when system has dynamic reference value and without this value, we can obtain up to $500 \%$ efficiency increase. The proposed approach may be easily expanded to the case of nonlinear system which will be shown by authors in their future publications.

\section{References}

[1] Bor-Sen Chen, Chung-Shi Tseng, Huey-Jian UangRobustness design on nonlinear dynamic system via fuzzy linear control // IEEE Transactions on fuzzy systems, vol. 7, No5, 1999, P. 571-585.

[2] Bondarenko N.A., Kolomijec V.V., Lutan S.N., Kobyljanskyy B.B. Investigation on dynamical characteristics of digital robust system for twochanel control of wrapping machine // Nauk. praci DonTU, series “Electrotechnics and energy", №1(14), 2013, P. 29-35. (in Russian) 
[3] F. Khaber, K. Zehar, A. Hamzaoui State feedback controller design via Takagi-Sugeno Model: LMI approach // Int. Journ. of Information and Mathematical Sciences 2:3 2006, P. 148-153.

[4] F. Lin. An optimal control approach to robust control design. International Journal of Control, 73(3):177-186, 2000.

[5] Erbatur, K., Kaynak, O. \& Sabanovic A. (1999). A Study on Robustness Property of Sliding Mode Controllers: A Novel Design and Experimental Investigations, IEEE Transaction on Industrial Electronics, Vol. 46, No. 5, pp. 1012-1018.

[6] Hace. A., Jezernik, K. \& Sabanovic, A. (2005). Improved Design of VSS Controller for a Linear Belt-Driven Servomechanism, IEEE/ASME Trans. on Mechatronics, Vol. 10, No. 4, pp. 385-390.

[7] Mohammad Mahdi Ebrahimi, Farzin Piltan, Mansour Bazregar, AliReza Nabaee Intelligent robust fuzzy-parallel optimization control of a continuum robot manipulator// Int. Journ. of Control and Automation, Vol.6, No.3 2013, P.15-34

[8] Potapenko E.M., Savranskaja A.V., Arsjenjeva S.I. Synthesis and analysis of robust robot control system // PAEP Theory and practice Kharkiv: Osnova, 1997 P. 165-168. (in Russian)

[9] S. Kohn-Rich, H. Flashner Robust fuzzy logic control of mechanical systems // Fuzzy Sets and systems 133 (2003), P. 77-108

[10] G. Ravitharan, Mahinda Vilathgamuwa, B.R. Duggal Robust field oriented control of induction motor// ICEM 2000, Espoo Finland, P.719-723.

[11] Guang Feng, Lipei Huang, Dongqi Zhu A robust nonlinear controller for inductiob motor// 14th Ifac, 1999, P. 103-108.

[12] Krzysztof Szabat, Teresa Orłowska-Kowalska and Piotr Serkies (2011). Robust Control of the Two-mass Drive System Using Model Predictive Control, Robust Control, Theory and Applications, Prof. Andrzej Bartoszewicz (Ed.), ISBN: 978-953-307-229-6, InTech, DOI: 10.5772/15730. Available from: http://www.intechopen.com/books/robust-control-theory-and-applications/robust-control-of-the-two-mass-drive-system-usingmodel-predictive-control

[13] Maciejowski J.M. Predictive control with constraints, 2002, Prentice Hall, UK.

[14] Cychowski M.T. Robust model predictive control, 2009, VDM Verlag.

[15] Bogdan Sasu Robust stability and stability radius for variational control systems// Abstract and applied analysis. Hindavi Publ.Corp. Vol 2008, Article ID 381791, 29 pages.

[16] Taih-Shyun Lee, Ye-Hwa Chen, Jason C.-H. Chuang Robust control design of fuzzy dynamical system//Applied Math. and Computations, 164, (2005), P.555-572.

[17] Shun-Hung Tsai, Tzuu-Hseng S. Li Robust fuzzy control of a class of fuzzy bilinear systems with time-delay//Chaos, Solitons \& Fractals (2007), doi:10.1016/j.chaos.2007.06.057

[18] S. Battilotti, A. De Santis Robust output feedback control of nonlinear stochastic system using neural networks// IEEE Transactions on neural networks, vol. 14, No.1 2003, P. 103-116.

[19] Marushchak Ja.Ju. Synthesis of electromechanical system with sequential and parallel correction - Lviv: Lviv Polytechnic Nation. Univ, 2005. 207 p. (in Ukrainian)

[20] F. Lin Robust Control Design. An Optimal Control Approach, 2007 John Wiley \& Sons Ltd., 378p.

[21] Polyak B.T., Tsypkin P.S. Robust stability and control, Moscow, Nauka 2002.-303p. (in Russian)

[22] D. Fodor, J. Vass, Zs. Juhasz, K.Biro Extended Kalman filter based speed sensorless AC motor control//9th Int.Conf on Power Electronics and Motion Control EPE-PEMC 2000 Kosice, P. 6140-6143.

[23] M. A. Duarte-Mermoud, R. Prieto Performance index for quality response of dynamical systems // ISA Transactions 43(2004), P. 133-151.

\title{
Аналіз ефективності застосування нечіткого регулятора двомасової системи зі змінним моментом інерції другої маси
}

\author{
Андрій Лозинський, Любомир Демків \\ Національний університет «Львівська політехніка», вул. С. Бандери 12, м. Львів, 79013, Україна
}

\section{Анотація}

У роботі розглянуто двомасову систему зі змінним моментом інерції другої маси. Досліджено загальні підходи до синтезу регулятора такої системи. Для такої системи було запропоновано використання робастного нечіткого регулятора. Було проведено порівняння пропонованого підходу з класичними. Зроблено відповідні висновки про доцільність використання пропонованого підходу. Було розглянуто випадки динамічної системи з еталонною моделлю і без неї. Крім того, були досліджені випадки лінійного та нелінійного характеру зміни другої маси. Отримані результати свідчать про те, що застосування запропонованого регулятора може забезпечити значний виграш в функціонуванні досліджуваної системи.

Ключові слова: нечіткий регулятор; робастний регулятор; двомасова система; МРС регулятор. 